\title{
QUANDO A INSTABILIDADE SE TORNA ESTÁVEL: POLIARQUIA, DESIGUALDADE SOCIAL E CULTURA POLÍTICA NA AMÉRICA LATINA
}

Marcello Baquero

\begin{abstract}
Resumo
Embora pouco estudada a relação entre desigualdade e promoção democrática na América Latina, não se pode ignorar que a forma como os cidadãos percebem a situação econômica do país, bem como sua própria situação material, podem comprometer o interesse no engajamento político. Neste trabalho, desenvolvese a idéia de que condições objetivas de desigualdade econômica e social na América Latina incidem na forma como os cidadãos percebem as instituições políticas e o grau de desapego em relação a elas. A conclusão sugere a necessidade de estabelecer políticas sociais de caráter distributivo para a promoção da democracia na sua dimensão maximalista.
\end{abstract}

Palavras-chave: Desigualdade; Democracia; América Latina; Instituições Políticas.

\begin{abstract}
Although few studies study the relationship between inequality and democratic promotion in Latin America, it cannot be ignored how citizens perceive the country's economic situation as well as their own economic situation, and how it impacts the decrease in political engagement. In this paper, the idea that objective adverse economic conditions influence the form that citizens perceive political institutions and the level of trust in them is developed. The conclusion points out to the need of establishing social policies of a distributive nature in order to promote democracy in its social dimension.
\end{abstract}

Key-words: Inequality; Democracy; Latin America; Political Institutions.

\section{Introdução}

Embora o enfoque predominante na Ciência Política, nas últimas décadas, tenha sido o institucional, não se pode negar que as condições econômicas, a cultura política, bem como o papel do cidadão são aspectos essenciais para compreender a evolução democrática de uma sociedade. A este respeito, Moisés (1995, p. 98) sugere que, embora a "cultura política não é suficiente para sozinha levar à mudança de um regime político, é, claramente, um elemento indispensável da sua construção social".

No caso da América Latina, com suas características sui generis, em determinados momentos históricos a ênfase na dimensão procedimental da democracia era inevitável. Por exemplo, após saírem 
de regimes de exceção, no início dos anos 1980, tornou-se imperativo, para essas nações, solidificar uma moldura institucional que servisse de base para a reconstrução democrática. Desse modo, era necessário criar regras, normas, leis e organizações políticas que revigorassem o contrato social. A prioridade, portanto, era o redesenho das organizações políticas para a qual a engenharia institucional era imprescindível. O pressuposto básico desse argumento é de que as instituições dão origem às normas, as quais, por sua vez, orientam o comportamento do indivíduo para fortalecer a instituição como sistema (DURSTON, 2002).

Decorre dessa perspectiva que, uma vez institucionalizado o método democrático (SCHUMPETER, 1976), os aspectos mais substantivos e subjetivos da democracia (dimensão social) se resolveriam automaticamente.

A acolhida majoritária da perspectiva institucionalista pela Ciência Política se dá com base nos fundamentos da filosofia liberal anglosaxônica derivada dos estudos de Adam Smith, John Locke e Stuart Mill, para quem o progresso econômico e político de um país é explicado pela doutrina econômica que enfatiza a ordem liberal e os direitos da propriedade. Tal posicionamento exclui o determinismo geográfico da explicação do subdesenvolvimento de sociedades. Ao mesmo tempo rejeita o enfoque da cultura política que enfatiza normas e valores como essenciais no desenvolvimento de uma nação.

A dimensão institucionalista coloca o subdesenvolvimento de um país como resultado da formatação da conduta humana pelas instituições. Se do ponto de vista da lógica formal e da dimensão normativa tal assertiva é difícil de ser contestada, a realidade contemporânea dos países da América Latina, na virada do milênio, mostra uma realidade divergente dos postulados da perspectiva institucionalista. Constata-se, atualmente, por exemplo, uma precariedade dos indicadores sociais - moradia, educação, saúde e segurança (CEPAL, 2005)-, aliada a uma percepção dos latinoamericanos de incerteza em relação ao futuro e crescente desconfiança nas instituições políticas e até em outras pessoas (LATINOBARÔMETRO, 
2005). Tal paradoxo tem motivado o ressurgimento de estudos com base na cultura política e no papel da sociedade civil no progresso democrático.

Nesse contexto, a valorização da perspectiva culturalista da democracia contemporânea não deve ser vista como alternativa ao enfoque institucionalista. Tal postura seria ingênua e reduziria o debate sobre os dilemas e desafios que a democracia contemporânea latinoamericana enfrenta a um mero exercício estéril. É óbvio que a sobrevivência e a eficiência do contrato social de uma sociedade precisa de instituições, leis e normas que regulem os conflitos sociais. A necessidade de boas e eficientes instituições para acelerar a institucionalização de uma democracia participativa e um melhor desenvolvimento econômico não está em questão.

O dilema, no caso da América Latina, diz respeito ao fato de que as instituições governamentais, e o mercado, não têm conseguido prover serviços sociais essenciais à população. Tal situação tem criado certa desconfiança dos cidadãos em relação às instituições formais, exigindo reformas eficientes e inclusivas da sociedade civil. Assim, a questão a ser respondida é: como se mudam as instituições, ou como torná-las mais responsivas e responsáveis? A esse respeito Dahl (2008) argumenta que, embora as instituições sejam necessárias, elas não são suficientes para alcançar uma democracia ideal, mas são as instituições, segundo o autor, que possibilitam dar um passo para o ideal democrático.

Da mesma forma, há um consenso nas sociedades desenvolvidas a respeito da necessidade de criar novas relações entre as instituições e os cidadãos para evitar uma crise de legitimidade (COLEMAN e GOTZE, 2008). Na medida em que os cidadãos têm se tornado menos dependentes e mais consumistas e voláteis, velhas modalidades de representação política têm sido questionadas. Do ponto de vista formal, o que se constata é um declínio na participação eleitoral, níveis reduzidos de participação política na vida cívica, ceticismo e cinismo em relação às instituições políticas e aos partidos, e o colapso das lealdades e adesões políticas.

REVISTA DEBATES, Porto Alegre, v. 2, n. 2, p. 48-69, jul.-dez. 2008. 50 
Penso que o que está em debate é a avaliação do porquê tais aspectos institucionais freqüentemente carecem de credibilidade e legitimidade aos olhos dos cidadãos desta região. Em um segundo momento, por que o fortalecimento democrático pleno no futuro parece problemático? Na medida em que se está lidando com seres humanos, a questão democrática se insere no debate entre o ideal e o real. Se, por um lado, definem-se metas a serem alcançadas numa perspectiva ideal de democracia, se essas metas não são alcançadas, é possível avaliar até que ponto se tem avançado de fato. Tal processo nos dá subsídios que avaliam o estágio atual de uma democracia.

Desse modo, creio que uma das respostas a estas perguntas reside na compreensão de como as predisposições das pessoas se estruturam e como se criam sistemas de crenças em que os sujeitos não aderem aos princípios democráticos, embora demonstrem apego à democracia num sentido genérico ou difuso. Tal assimetria parece ocorrer mais reincidentemente em países em desenvolvimento, onde a desigualdade e a exclusão social são aspectos predominantes, ao contrário dos países desenvolvidos onde seu sucesso parece estar relacionado à provisão universal de educação básica e serviços de saúde, bem como ao estabelecimento de Estados de bem-estar altamente distributivos (BID, 2000), é o que têm proporcionado o desenvolvimento de valores pós-materialistas (INGLEHART, 1977).

Neste sentido, problematizar o papel da cultura política na construção democrática dos países latino-americanos é o objetivo central deste trabalho. Partimos do pressuposto de que instituições e cultura política fazem parte de um continuum cuja centralidade depende do contexto e das condições da construção democrática. Dentro desse contexto, o estado das condições materiais mínimas tem papel decisivo, em nossa opinião, no fortalecimento, ou não, de uma cultura política democrática.

REVISTA DEBATES, Porto Alegre, v. 2, n. 2, p. 48-69, jul.-dez. 2008. 51 


\section{Democracia Formal, Desigualdade Econômica e Participação Política}

Embora não se possa desconsiderar os avanços significativos alcançados na dimensão poliárquica (DAHL, 1971) na América Latina, constatados no Relatório do Programa das Nações Unidas para o Desenvolvimento - PNUD (2004), o qual indica que os índices objetivos da democracia (reforma econômica, índice de desenvolvimento eleitoral e o crescimento do Produto Interno Bruto - PIB) têm avançado significativamente, quando se examinam os indicadores sociais (pobreza, indigência, coeficiente de GINI e desemprego urbano) os resultados não são alentadores. De maneira geral, essas dimensões têm estagnado ou piorado no período de 1983-2003. No que diz respeito ao crescimento econômico na América Latina, as décadas recentes mostram que o mesmo tem sido moderado e instável, constituindo-se num problema crônico da região e cujas manifestações recentes têm sido mais notórias e perniciosas do que no passado (ALONSO, 2007). Nem mesmo os crescentes ritmos de crescimento dos últimos anos têm sido suficientes para fortalecer os mercados de trabalho e reduzir de modo satisfatório a incidência da pobreza, produzindo o que Hoffman e Centeno (2004) denominam de continente invertido para assinalar que a distribuição de bens, serviços e oportunidades básicas na América Latina são desequilibradas.

Nessas circunstâncias, e do ponto de vista da cultura política, não surpreende a existência de uma incongruência entre avanços formais da democracia, estagnação social e predisposições e percepções negativas dos cidadãos em relação à democracia e suas instituições, produzindo um processo de desengajamento cívico (PUTNAM e GOSS, 2002), desinstitucionalização democrática (SANCHEZ-PARGA，2001; SILVA, 2004), e democracia inercial (BAQUERO, 2007). O teorema que deriva dessa análise é de que quando a magnitude da desigualdade social e econômica é elevada, compromete a solidez democrática, mantendo-a numa condição de permanente instabilidade, ou de baixa qualidade, na medida em que sociedades altamente desiguais promovem elevados índices de corrupção e baixos índices de confiança social.

REVISTA DEBATES, Porto Alegre, v. 2, n. 2, p. 48-69, jul.-dez. 2008. 52 
Da mesma forma que a teoria econômica identifica a acumulação de capital físico e humano e o progresso tecnológico como sendo os principais fatores de crescimento econômico e desenvolvimento democrático, a perspectiva institucional da Ciência Política sugere que boas instituições e leis eficientes produzem sistemas democráticos plenos. Essa afirmação, também conhecida como a teoria da transição, pressupõe que a liberdade do mercado promove regimes democráticos, e estes, por sua vez, contribuem para o bem-estar econômico (LYNN, 1996). Nessa perspectiva, a participação política é de caráter formal e procedimental, sendo o voto o aspecto central. Não se incentiva, portanto, outras modalidades de participação mais direta. Essa afirmação remete a outra questão de caráter individual e que diz respeito, segundo Dahl (2008, p. 21) "ao fato de que instituições políticas são necessárias para que um sistema político se qualifique como uma democracia". A democracia a qual Dahl se refere é de natureza minimalista.

No caso da América Latina, observa-se uma persistência tenaz de desigualdade político-econômica, de pobreza e de exclusão social. $\mathrm{Na}$ tentativa de compreender esse paradoxo, com base na dimensão poliárquica mais ampliada, O'Donnell (1998) argumenta que a cidadania de baixa intensidade que se observa na América Latina deriva da permanência da pobreza, da elevada concentração de renda e de outras formas de discriminação que, de uma forma ou de outra, produzem relações sociais autoritárias. Tais elementos desafiam as interpretações ortodoxas e predominantes na Ciência Política, sinalizando a necessidade de refletir a respeito de outras explicações que identifiquem os fatores que determinam o fortalecimento de uma democracia no seu sentido social.

A primeira constatação a este respeito deriva do Relatório da CEPAL (2007) que mostra que três décadas de democracia formal não têm conseguido reduzir as desigualdades sociais. Da mesma forma, Espina (2008, p. 18-19) argumenta que 
la desigualdad latinoamericana tiene características típicamente oligárquicas y que la asimetría de la distribución de ingresos se acumula considerablemente en el segmento superior.

Nesse sentido, falar em regimes de bem-estar em países em desenvolvimento, como na região latino-americana, pode distorcer a realidade da maioria da população. A premissa do círculo virtuoso que postula que mais democracia produz justiça social e mais justiça social gera mais democracia não tem se materializado. Os dados da CEPAL mostram o contrário: no mundo globalizado, os países da América Latina, com raras exceções, têm aumentado as desigualdades sociais, não têm conseguido resolver adequadamente a dimensão material e têm precarizado a situação da classe média. São estes fatores que, segundo o PNUD (2004), erosionam a legitimidade da democracia nesta região.

De acordo com Hoffman e Centeno (2004), o crescimento eqüitativo nunca existiu na América Latina. Segundo eles, seria mais fácil reduzir substancialmente os níveis de miséria e pobreza via mudanças na distribuição do que via crescimento real. Nessas circunstâncias, os fatores que decorrem de desigualdade econômica e social, tais como: a falta de respeito pela lei, a corrupção e a ineficácia dos governos na promoção de serviços essenciais básicos que proporcionem uma melhor qualidade de vida aos latino-americanos se constituem numa barreira que impede o progresso econômico e o desenvolvimento social.

Nessa conjuntura, os movimentos sociais que têm emergido, entre outros fatores, pela incapacidade das instituições formais de mediação política em regular os conflitos sociais, mais do que ampliar a democracia representativa, buscam estabelecer novas práticas e novos modelos políticos com base na experiência autóctone e na diversidade cultural como modelos superadores da democracia precedente (BURCHARDT, 2008). Dessa maneira, os questionamentos sobre a concepção universalista subjacente à perspectiva institucionalista têm se acentuado. De acordo com Burchardt (2008), tal perspectiva não tem 
conseguido desenvolver uma nova proposta para superar o fracasso da representação política dos grupos tradicionalmente excluídos da arena política, bem como não tem conseguido superar a incapacidade de incluir práticas autóctones de participação na sua concepção de democracia.

No âmago desta problemática está a existência de uma base material não resolvida e para a qual não se vislumbra, em um futuro próximo, soluções viáveis. Até recentemente, pouco se sabia a respeito da vinculação entre desigualdade econômica e mudanças nas predisposições atitudinais e no comportamento político dos cidadãos. No entanto, pesquisas desenvolvidas nos últimos anos têm constatado que a desigualdade econômica deprime significativamente o interesse, a discussão e a participação política da maioria das pessoas.

Um desses estudos é o de Dahl (2008), que assume como dado que a desigualdade econômica diminui o engajamento político, particularmente entre os mais necessitados. Na mesma direção Solt (2008) demonstra que a desigualdade econômica deprime, de forma significativa, o interesse por política, a discussão sobre política e a participação em eleições com exceção dos mais afluentes. Ainda segundo esse autor, o engajamento político de uma pessoa não depende unicamente da quantidade de recursos financeiros que ela possui, mas dos recursos materiais dos outros.

Em contextos onde os recursos são distribuídos equitativamente, o poder é distribuído, também, eqüitativamente, tendo como resultado o estímulo para que as pessoas com menos posses participem da política, enquanto que quanto maior a desigualdade econômica maior a distorção da democracia a favor dos mais ricos e, como conseqüência, faz com que os cidadãos cheguem à conclusão que não vale a pena participar da arena política. Este enfoque é desenvolvido na chamada teoria relativa do poder. Para Dahl (2008, p. 19), a igualdade política é

um juízo moral pelo que todos os seres humanos têm o mesmo valor intrínseco, nenhuma pessoa é instrinsicamente superior a outra e que se deve dar 
igual consideração ao bem ou aos interesses de cada pessoa.

Nessa perspectiva, num contexto de desigualdade e concentração de renda, as experiências negativas que as pessoas têm ou tiveram com instituições políticas formais proporcionaram a matriz sobre a qual se institucionalizou o pensamento dos cidadãos, excluídos das políticas públicas, de que sua condição material era natural, ou como Freire (1970) argumenta, internalizaram a figura do dominador, desenvolvendo um pensamento mágico que os faz acreditar que eles merecem estar nessa situação.

Em oposição a essa linha de pensamento, autores que se identificam com a chamada teoria do conflito (BRADY, 2003) argumentam que a desigualdade econômica incide positivamente no engajamento político das pessoas. Tal posicionamento se dá com base no princípio de que desigualdade produz divergências nas preferências de políticas públicas, tendo como corolário uma maior mobilização política. Nessas condições, o aumento da mobilização política dos mais excluídos, exigindo políticas públicas redistributivas, geraria conflito com as classes mais abastadas, que se posicionam contra dispositivos redistributivos, que se materializariam em aumento da carga tributária para eles, com a qual não estão dispostos a arcar. Esse confronto em relação ao rumo das políticas públicas redundaria no aumento de conflitos, incidindo no progresso democrático de uma sociedade.

Numa perspectiva mais empírico-objetiva denominada de teoria dos recursos, o impacto da desigualdade econômica no engajamento político das pessoas pode ser positivo ou negativo, dependendo da renda de cada indivíduo. É, basicamente, uma abordagem de custos e benefícios. Esta dimensão teórica sugere que, onde existem níveis elevados de desigualdade econômica, a transição para a democracia é mais difícil, na medida em que a democracia existente favorece os mais influentes, levando à conclusão dos atores excluídos de que é um jogo do qual não vale a pena participar. Nessas circunstâncias, a capacidade distributiva do Estado está assimetricamente estabelecida, pois os 
gastos sociais não significam, necessariamente, que se dêem numa direção redistributiva.

$\mathrm{Na}$ mesma direção, do ponto de vista da teoria de escolha racional, a conclusão da maioria dos cidadãos em relação à opção de não se envolver com a política radica na constatação de um sistema político que tem fracassado na implementação de políticas públicas distributivas, acentuando a descrença nessas instituições e estimulando o desengajamento político. É neste sentido que a desigualdade material incide nas percepções negativas que a população desenvolve em relação à política, às suas instituições e aos seus representantes eleitos.

Outra linha de pensamento presente na Ciência Política é aquele que postula a relação causal entre democracia e desenvolvimento econômico. Para muitos autores (HUNTINGTON, 1968), na medida em que as democracias precisam responder a demandas sociais imediatas da população, acabam comprometendo investimentos de longo prazo e, por decorrência, a promoção democrática. Implícito nesse argumento está a idéia de que, em alguns casos, torna-se necessário tomar medidas coercitivas e autoritárias para garantir a governabilidade a longo prazo. Nessa perspectiva, é o mercado que tem prioridade e a democracia pode ser considerada secundária em países em desenvolvimento.

Indo de encontro a estes posicionamentos, North (1990) defende a hipótese que relaciona os efeitos independentes da democracia no crescimento econômico a partir do postulado que coloca as instituições políticas como as salvaguardas de eventuais desvios das autoridades constituídas. Assim, para o autor a implementação da regra da lei, o comprimento de contratos e a proteção dos direitos de propriedade não requerem necessariamente regimes autoritários. Desse ponto de vista se atribui peso determinante à estrutura organizacional e às organizações em relação ao regime na promoção do desenvolvimento material de uma nação.

A virada da equação democracia-desenvolvimento para desenvolvimento institucional-democracia parte da premissa que fatores tais como: regra da lei, empoderamento, fiscalização, transparência, 
corrupção e instabilidade política eram vistos como elementos influenciados pelo estágio de uma democracia política. Presentemente, para os autores que defendem a relação instituições-crescimentodemocracia, esses fatores são vistos como importantes mecanismos que resultam do crescimento econômico elevado. A hipótese subjacente a este pensamento é de que as instituições democráticas ajudam o mercado a funcionar perfeitamente como nos modelos econômicos neoclássicos (RODRIK, 1999). Além do mais, Rodrik constatou correlações significativas entre a dimensão institucional e a democracia política.

De que modo as sociedades latino-americanas se enquadram dentro dessa discussão? Em primeiro lugar, cabe destacar que a despeito de diferenças culturais, históricas, políticas e econômicas, essa região parece ter uma homogeneidade quando se analisa sua situação socioeconômica.

Dados disponíveis em várias instituições (CEPAL, Banco Mundial) mostram que o desempenho econômico da América Latina enquanto região tem sido desalentador. A desigualdade de renda se mantém elevada, a exclusão social, medida pelo coeficiente de GINI, apesar de suas deficiências metodológicas, também tem se mantido inalterada. Esses elementos têm sido decisivos e têm impedido a redução significativa da desigualdade e da exclusão social.

Ilustrativa dessa situação é a constatação de que crianças oriundas de famílias pobres e pais com pouca escolaridade têm uma probabilidade relativamente elevada de alcançar níveis educacionais baixos, obtendo retornos reduzidos pela sua educação e, portanto, mantendo-se na pobreza (BID, 2000). Em estudo recente, Alonso (2007) constatou que metade dos latino-americanos, quando indagados a respeito dos principais problemas encontrados nos seus países, identificaram os seguintes: desemprego, baixos salários, inflação, pobreza e instabilidade no emprego. Tais preocupações se materializam simultaneamente num momento em que o Índice de Desenvolvimento Humano tem aumentado, bem como a expectativa de vida, ao mesmo 
tempo em que a taxa de mortalidade infantil e o analfabetismo têm diminuído. Então por que persistem a desigualdade e a exclusão social?

$\mathrm{Na}$ dimensão política, os avanços institucionais, como foi dito, são visíveis. No entanto, também é visível a falta de respeito pela lei, tanto por parte das autoridades quanto dos cidadãos, o aumento da corrupção em todos os níveis, a incapacidade ou ineficiência dos governos de plantão em desenhar e implementar políticas públicas sociais redistributivas e a violação dos direitos humanos. Nessas circunstâncias, materializa-se o paradoxo das sociedades latinoamericanas, que convivem simultaneamente com um regime democrático formal e com elevados déficits sociais que comprometem o progresso econômico e o desenvolvimento social, produzindo o que se denomina de uma democracia inercial (BAQUERO, 2007).

De acordo com Burchardt (2008), apesar das organizações internacionais, como o PNUD, terem identificado as desigualdades sociais como o problema central da América Latina, as recomendações para solucionar esse problema continuam a dar-se dentro de uma abordagem institucionalista, mantendo a desigualdade social em patamares elevados.

Um dos problemas em considerar as instituições como sendo o único mecanismo de fortalecimento democrático diz respeito à forma como este termo é conceituado. Por ser um conceito polissêmico, vários são seus significados. Num sentido mais reduzido, as instituições são definidas como regras formais do jogo que formatam os incentivos e constrangimentos individuais (TABELLINI, 2005).

Num sentido mais amplo, as instituições podem também incluir sistemas de crença ou normas sociais que dão sustentação a um equilíbrio específico (GLAESER et al., 2004). Tal enfoque subscreve majoritariamente a uma perspectiva mais ampla, na medida em que permite mensurar instituições de direito de propriedade ou instituições políticas via indicadores de resultados, e não por códigos formais ou constitucionais. Isto torna difícil estabelecer uma relação de causaefeito. Se as mesmas instituições formais funcionam diferentemente em contextos sociais e econômicos diferentes, então os resultados 
institucionais e econômicos são simultaneamente determinados, e a perspectiva que atribui um efeito causal independente às instituições se torna tênue. Nessa direção, Glaeser et al. (2004) argumenta que o impacto da história de uma sociedade no desenvolvimento econômico atual é um reflexo do acúmulo de capital humano, o qual, por sua vez, influencia os resultados institucionais, e não o contrário.

Nessa mesma linha de análise, Lipset (1959) considera que a educação tem papel decisivo na evolução das instituições. Especificamente em relação à legitimidade de um sistema político Lipset considera que os traços culturais e a educação desempenham um papel decisivo, pois para o autor a democracia funciona bem quando os cidadãos a aceitam como instrumento legítimo de resolução de conflitos.

Um aspecto comum às diferentes perspectivas teóricas acima discutidas é o caráter secundário que elas atribuem ao cidadão no processo político. A ênfase para explicar o processo e progresso tecnológico está baseada na história, na economia e nas instituições preponderantemente. Neste trabalho, considero todas essas abordagens válidas para algum momento na história isolada ou conjuntamente. No entanto, proponho que no momento atual da democracia latinoamericana, na medida em que as instituições estão razoavelmente estabelecidas, o dilema da instabilidade política deve ser compreendido com base em outras dimensões, sendo uma delas a forma como a cultura política se desenvolve.

Neste contexto, parte-se do pressuposto de que o desejo ou predisposição dos cidadãos para cooperar em prol de objetivos coletivos assume centralidade, pois as instituições não podem funcionar efetivamente quando não existe confiança nelas, ou quando a dimensão econômico-social não está adequadamente resolvida. Nesse sentido, a forma como os cidadãos percebem sua situação sócio-econômica influencia as suas atitudes em relação às instituições políticas. A equação instituições-democracia, portanto, é revertida para a equação na qual a política impacta o processo democrático, ou seja, a forma como os valores cívicos são estruturados proporciona, ou não, as bases 
da legitimidade e estabilidade política, e, esses valores derivam da percepção que os cidadãos têm de sua condição material.

Vista dessa forma, neste trabalho se argumenta que a democracia depende, significativamente, para funcionar de forma eficiente (regular os conflitos sociais) e plenamente (satisfazendo minimamente as demandas de caráter social), do grau de apoio que os cidadãos dão ao regime político vigente, ou seja, do tipo de cultura política existente num país.

Enfatizar o conceito de cultura política, também, não está isento de complexidades conceituais e metodológicas, sobretudo no que diz respeito aos aspectos sociométricos. Nesse sentido, reconhecendo os limites de pesquisas que trabalham com percepções dos cidadãos, tenta-se identificar se a adesão a valores e práticas políticas tradicionais influencia o grau de aceitação ou rejeição das instituições tipicamente de democracia formal.

A noção de que a cultura está associada ao desenvolvimento econômico e ao progresso democrático não é nova na Ciência Política. Encontram-se argumentos nessa direção nos trabalhos de Tocqueville (1990), Weber (1983), Huntington (1968) e Almond e Verba (1963), para mencionar os mais citados. Mais recentemente, o estudo de Banfield (1988) sobre o familismo amoral e a pesquisa de Putnam (1996) a respeito das diferenças entre o norte e o sul da Itália em relação à produção de capital social, apontam que tais diferenças podem ser atribuídas a diferentes histórias e tradições, e que esses fatores são explicações potenciais de diferentes níveis de desenvolvimento econômico e político, bem como dimensões que explicam por que se constrói capital social num contexto e não em outro.

De acordo com Putnam (1996), as pessoas se envolvem nos gastos públicos e cívicos quando adquirem o hábito de conexão comunitária; na medida em que esses hábitos desaparecem, o envolvimento político se atrofia. Independente de se concordar ou não com a argumentação de Putnam, não se pode ignorar que a maior parte dos países desenvolvidos e em desenvolvimento está experimentando o 
colapso da confiança nos moldes tradicionais da governança democrática.

\section{A dimensão empírica das condições materiais e cultura política}

Para avaliar o impacto da desigualdade sócio-econômica nas predisposições políticas dos cidadãos latino-americanos, utilizamos dados de pesquisa comparativa tipo survey realizada em Montevidéu/ Uruguai, Santiago/ Chile e Porto Alegre/ Brasil, com 500 entrevistas nas duas primeiras e 510 na última, via amostragem probabilística em 2005 (NUPESAL/UFRGS).

Um dos pontos centrais que afetam as percepções dos cidadãos em relação à democracia e suas instituições está baseado na situação econômica. Para avaliar esta dimensão, utilizamos uma bateria de perguntas que indaga a respeito das dificuldades, ou não, das pessoas em adquirir bens considerados essenciais para uma melhor qualidade de vida. Perguntamos se os entrevistados têm dificuldades para obter ou pagar por esses bens materiais essenciais. Os dados estão na Tabela 1.

Tabela 1- Em geral o sr./sra. teve ou tem dificuldade para pagar ou obter (\%)

\begin{tabular}{c|c|c|c|c}
\hline & Porto Alegre & Montevidéu & Santiago do Chile & Média \\
\hline Alimentação & 41,2 & 42,0 & 49,4 & 44,2 \\
\hline Medicamento & 48,0 & 45,0 & 53,0 & 48,6 \\
\hline Luz & 44,0 & 40,0 & 48,0 & 44,0 \\
\hline Água & 39,8 & 37,0 & 47,0 & 41,2 \\
\hline Vestuário & 53,0 & 54,0 & 49,0 & 52,0 \\
\hline Transporte & 40,0 & 39,0 & 48,0 & 42,3 \\
\hline Telefonia & 46,0 & 45,0 & 50,0 & 47,0 \\
\hline Moradia & 39,4 & 36,2 & 31,3 & 35,6 \\
\hline Total $(\mathrm{n})$ & 510 & 500 & 500 &
\end{tabular}

Fonte: Pesquisa Capital Social e Desenvolvimento Sustentável na Promoção da Cidadania e da Qualidade de Vida na América Latina, 2005. NUPESAL/UFRGS

Do ponto de vista da média para as três cidades pesquisadas se constata que o item vestuário foi considerado pelos entrevistados como o mais difícil para obter ou pagar (52\%), seguido por medicamentos $(48,6 \%)$, telefonia (47\%) e alimentação (44,2\%). Uma segunda constatação se refere ao fato de que Santiago do Chile é a cidade que 
apresenta as maiores porcentagens de obter ou pagar a maior parte dos itens analisados, principalmente na questão dos medicamentos $(53,0 \%)$.

Deduz-se desses dados que, quando cerca da metade da população de importantes cidades na América Latina enfrenta dificuldades para conseguir o mínimo necessário para garantir uma qualidade de vida decente, tal situação pode incidir na desconfiança que as pessoas sentem em relação às instituições políticas e nos representantes políticos. É este o tema que passamos a examinar.

As instituições públicas são, por natureza, a materialização da expressão, das opiniões e dos sistemas de crença dos atores sociais numa sociedade. É por meio delas que os cidadãos tentam resolver seus problemas coletivos. Nesse sentido, o processo de mediação exige a existência de regras e práticas de convivência e solução de conflitos regidos pelo equilíbrio e pela obediência à lei. No entanto, a realidade tem mostrado que a relação entre instituições e cidadãos não tem primado por um respeito mútuo e, muito menos pela obediência às regras estabelecidas. Quando isso ocorre e se mantém estruturalmente ao longo do tempo, o resultado é a fragilidade do contrato social e a instabilidade permanente, incidindo no afastamento dos cidadãos da política e na crescente desconfiança nas instituições políticas. Quando a desigualdade persiste, a tendência é a materialização de uma polarização sócio-econômica, impactando os padrões de distanciamento dos cidadãos, não só em relação as instituições políticas, mas, também, a confiança interpessoal. Tal situação fica clara quando se examinam as opiniões dos latino-americanos sobre as principais instituições da democracia representativa, e seu grau de envolvimento em instituições formais e informais. 
Tabela 2 - Desconfiança e participação nas instituições políticas (\%)

\begin{tabular}{|c|c|c|c|c|c|c|c|c|c|c|c|c|c|c|}
\hline & \multicolumn{6}{|c|}{ Porto Alegre } & \multicolumn{5}{|c|}{ Montevidéu } & \multicolumn{3}{|c|}{ Santiago do Chile } \\
\hline & $\begin{array}{c}\text { Congresso } \\
\text { (não } \\
\text { confia) }\end{array}$ & $\begin{array}{c}\text { Governo } \\
\text { municipal } \\
\text { (não } \\
\text { confia) }\end{array}$ & $\begin{array}{c}\text { Câmara } \\
\text { municipal } \\
\text { (não } \\
\text { confia) }\end{array}$ & $\begin{array}{l}\text { Assembléia } \\
\text { Legislativa } \\
\text { (não confia) }\end{array}$ & $\begin{array}{c}\text { Participa } \\
\text { de } \\
\text { grupos }\end{array}$ & $\begin{array}{c}\text { Participa } \\
\text { de } \\
\text { partidos }\end{array}$ & $\begin{array}{c}\text { Congresso } \\
\text { (não confia) }\end{array}$ & $\begin{array}{c}\text { Governo } \\
\text { municipal } \\
\text { (não } \\
\text { confia) }\end{array}$ & $\begin{array}{c}\text { Câmara } \\
\text { municipal } \\
\text { (não } \\
\text { confia) }\end{array}$ & $\begin{array}{l}\text { Participa } \\
\text { de } \\
\text { grupos }\end{array}$ & $\begin{array}{c}\text { Participa } \\
\text { de } \\
\text { partidos }\end{array}$ & $\begin{array}{c}\text { Congresso } \\
\text { (não } \\
\text { confia) }\end{array}$ & $\begin{array}{l}\text { Câmara } \\
\text { municipal } \\
\text { (não } \\
\text { confia) }\end{array}$ & $\begin{array}{c}\text { Participa } \\
\text { de } \\
\text { partidos }\end{array}$ \\
\hline Saúde & 33,9 & 24,8 & 26,8 & 28,9 & 15,9 & 5,8 & 19,5 & 3,6 & 19,7 & 19,6 & 10,7 & 26,2 & 35 & 0 \\
\hline Educação & 34,6 & 27,4 & 30,7 & 31,6 & 14,6 & 3,6 & 19,8 & 13,2 & 19,5 & 21,8 & 11,7 & 27,8 & 29,2 & 2,1 \\
\hline Lazer & 36,2 & 26,9 & 31 & 32 & 15,3 & 4,6 & 18,8 & 12,8 & 18,6 & 22,8 & 11,9 & 31 & 29,9 & 0,9 \\
\hline Transporte & 38,1 & 28,2 & 32 & 33,4 & 15,6 & 5,1 & 20,3 & 13 & 19,2 & 21,7 & 10,2 & 24,6 & 25,9 & 1,9 \\
\hline Segurança & 33,5 & 22,5 & 28 & 29,8 & 15 & 3,7 & 15 & 9,7 & 14,1 & 22,6 & 12,2 & 27,3 & 15,6 & 3,1 \\
\hline Saneamento & 37,2 & 26,8 & 30,2 & 31,5 & 17,3 & 4,6 & 19,9 & 13,9 & 19,6 & 21,3 & 12,9 & & & \\
\hline Habitação & 31,5 & 26,7 & 28,9 & 29,2 & 16,2 & 4 & 20,3 & 12,5 & 18,2 & 20,1 & 10,4 & 27,3 & 24,7 & 3,4 \\
\hline Telefonia & 37,9 & 28,7 & 32 & 33,4 & 14,4 & 4 & 21,9 & 15,6 & 20,6 & 20,8 & 11,8 & 37,7 & 31 & 2,6 \\
\hline Média & 35,4 & 26,5 & 30 & 31,2 & 15,5 & 4,4 & 19,4 & 13 & 18,7 & 21,3 & 11,5 & 28,8 & 27,3 & 2 \\
\hline
\end{tabular}

Fonte: Pesquisa Capital Social e Desenvolvimento Sustentável na Promoção da Cidadania e da Qualidade de Vida na América Latina, 2005. NUPESAL/UFRGS n (Porto Alegre) $=510, n$ (Montevidéu) $=500, n$ (Santiago do Chile)=500. NUPESAL/UFRGS 
$\mathrm{Na}$ Tabela 2, examina-se o cruzamento entre ter dificuldades para pagar ou conseguir itens considerados essenciais para uma melhor qualidade de vida com a desconfiança no Congresso (esfera federal), no legislativo (estadual) e no município (Câmara Municipal e governo municipal), bem como a participação política em grupos ou associações e em partidos políticos.

Constata-se, em primeiro lugar, haver uma diferença entre as três cidades analisadas. Em Montevidéu, verifica-se que entre as pessoas que tiveram dificuldades para pagar ou obter os itens mencionados se mantêm os mesmos índices de desconfiança no Congresso Nacional. Já no que se refere à Câmara Municipal e ao governo municipal a desconfiança também se mantém dentro de uma média $(13 \%)$, porém, cabe ressaltar que os níveis de desconfiança são menores do que em relação ao Congresso $(19,4 \%)$. No caso do Chile, o mesmo padrão se observa, só que num ponto intermediário $(28,8 \%)$ entre Montevidéu e Porto Alegre.

No que se refere à participação em grupos e/ou associações, os uruguaios são os que mais participam dessas instâncias $(21,3 \%)$, seguidos por porto-alegrenses (15,3\%).

Em suma, os dados mostram que os níveis de desconfiança dos entrevistados é mais elevado em Porto Alegre, seguido por Santiago do Chile e Montevidéu, sugerindo que uma porcentagem significativa das pessoas que têm dificuldades para conseguir serviços essenciais são as que mais desconfiam das instituições políticas. $O$ dado mais interessante, porém, diz respeito à baixa porcentagem de latinoamericanos que participam, de alguma forma, nos partidos políticos ( $2 \%$ no Chile, 4,4\% em Porto Alegre e 11,5\% em Montevidéu), revelando um afastamento da principal instituição de mediação política. No que se refere à participação em grupos, os dados, embora um pouco mais elevados, revelam baixos índices de participação comunitária e associativa.

Poder-se-ia inferir dos dados uma situação de desinteresse e desmobilização dos cidadãos entrevistados, tanto da esfera formal da 
política quanto da esfera informal. Fatores estes que pouco contribuem para fortalecer o governo democrático.

\section{Considerações Finais}

O objetivo deste artigo foi o de examinar de que forma as percepções dos latino-americanos em três cidades (Porto Alegre, Montevidéu e Santiago do Chile) a respeito da dimensão material na sociedade em que estão inseridos impactam suas percepções e comportamentos na política. O estudo dessas predisposições atitudinais e comportamentais tem implicações importantes para compreender a baixa qualidade da democracia nesses países, principalmente quando se leva em conta a dimensão social.

Numa análise preliminar, os dados deste trabalho sinalizam que a percepção da desigualdade dos entrevistados, operacionalizada em termos de enfrentar dificuldades para pagar ou obter serviços essenciais, desencoraja a participação política tanto na dimensão formal quanto na informal.

Da mesma maneira, a presença da desigualdade, na medida em que impacta negativamente no pluralismo cultural e a diferença social produzindo e mantendo a pobreza social, reforça os padrões de desigualdade e ameaça privar as sociedades daqueles fatores essenciais para o progresso democrático, tais como: laços sociais, confiança recíproca, empoderamento, alteridade e cooperação social reflexiva.

Essa conclusão aponta para a necessidade de estabelecer políticas sociais de caráter distributivo, sob pena de manter a democracia numa dimensão inercial, ou seja, mesmo que se constate um crescimento econômico, tal crescimento não é direcionado para maiores investimentos nas áreas sociais.

Finalmente, este estudo confirma a hipótese de que sociedades nas quais os cidadãos percebem que os níveis de desigualdade os afetam diretamente contribuem significativamente para diminuir suas perspectivas para se envolver em ações políticas tanto de caráter formal quanto comunitário. Nesse contexto, consolidar a democracia na sua 
dimensão social torna-se bastante difícil e pode comprometer, em médio prazo, os ganhos obtidos na dimensão poliárquica.

Marcello Baquero é PhD. em Ciência Política pela Florida State University, pós-doutor em Ciência Política pelo Instituto Gini Germani (2006) e no Institute of Development Studies/ University of Sussex (2007), professor do Programa de Pós-Graduação em Ciência Política da Universidade Federal do Rio Grande do Sul e coordenador do Núcleo de Pesquisas sobre a América Latina.

E-mail: nupesal@yahoo.com.br

\section{Referências:}

ALMOND, Gabriel; VERBA, Sidney. The civic culture: political attitudes and democracy in five nations. Boston: Little Brown e Co., 1963.

ALONSO, Antonio J. Desigualdad, instituciones y progreso: un debate entre la historia y el presente. Revista de la CEPAL, Santiago/Chile, n. 23, p. 63-84, dez. 2007.

BANCO INTERAMERICANO DE DESARROLLO (BID). Desarrollo: Más allá de la economía. Progreso económico y social en América Latina. Washington D.C.: BID, 2000.

BANFIELD, Edward C. The moral basis of a background society. New York: Free Press, 1988.

BAQUERO, Marcello. Democracia e desigualdades na América Latina: novas perspectivas. Porto Alegre: Editora UFRGS, 2007.

BRADY, Henry. An analytical perspective on participatory inequality and income inequality. In: NECKERMAN, Kathryn M. (Ed.). Social Inequality. New York: Russel Sage Foundation, 2003. p. 667-702.

BURCHARDT, Hans-Jürgen. Desigualdad y democracia. Nueva Sociedad, Caracas, n. 215, p. 79-94, mai.-jun. 2008.

COLEMAN, Stephen; GOTZE, John. Bowling together: online public engagement in policy deliberation. London: Hansard Society, 2008.

COMISIÓN ECONÓMICA PARA AMÉRICA LATINA (CEPAL). Anuário estadístico de América Latina y el Caribe. Santiago do Chile: CEPAL, 2005. 
. Anuário estadístico de América Latina y el Caribe. Santiago do Chile: CEPAL, 2007.

DAHL, Robert Alan. Poliarchy: Participation and opposition. New Haven and London: Yale University Press, 1971.

. La igualdad política. Buenos Aires: Fondo de Cultura Econômica de Argentina, 2008.

DURSTON, John. El capital social campesino en la gestión del desarrollo rural: díadas, equipos, puentes y escaleras. Santiago do Chile: CEPAL, 2002.

ESPINA, Álvaro. Modernización, estadios de desarrollo económico y regímenes de bienestar en América Latina. Madrid: Fundación Carolina, 2008.

FREIRE, Paulo. Pedagogia do oprimido. Rio de Janeiro: Paz e Terra, 1970.

GLAESER, Edward; PORTA, Rafael La; LOPES-DE-SILANES, Florencio; SHLEIFER, Andrei. Do institutions cause growth? Journal of Economic Growth, New York, v. 9, n. 3, p. 271-303, springer 2004.

HOFFMAN, Kelly; CENTENO, Miguel. El continente invertido: desigualdades en América Latina. Nueva Sociedad, Caracas, n. 193, p. 97-111, set.-out. 2004.

HUNTINGTON, Samuel. Political order in changing societies. New Haven and London: Yale University Press, 1968.

INGLEHART, Ronald. The silent revolution. Princeton: Princeton University Press, 1977.

LATINOBARÔMETRO. 2005. Informe Latinobarômetro 2005. Disponível em: <http://www.latinobarometro.org/>. Acesso em: 8 nov. 2008.

LIPSET, Seymour Martin. Some social Requisites of Democracy: economic development and political legitimacy. The American Political Science Review, Washington, D.C., v. 53, n. 1, p. 69-105, mar. 1959.

LYNN K., Terry. Dilemmas of democratization in Latin America. In: CAMP, Roderic Ai. Democracy and Development in Latin America: patterns and cycles. Delaware: Scholarly Resources Inc, 1996. p. 21-46.

MOÍSES, José Álvaro. Os brasileiros e a democracia: bases sóciopolíticas de legitimidade democrática. São Paulo: Ática, 1995.

NORTH, Douglas. Institutions, Institutional Change and Economic performance. Cambridge: Cambridge University Press, 1990. 
O'DONNELL, Guillermo. Poverty and inequality in Latin America: some political reflections. In: TOKMAN, Victor; O'DONNELL, Guillermo (Eds.). Poverty and inequality in Latin America: issues and new challenges. Notre Dame: University of Notre Dame Press, 1998. p. 49-74.

PROGRAMA DE LAS NACIONES UNIDAS PARA EL DESARROLLO (PNUD). La democracia en América Latina: hacia una democracia de ciudadanas y ciudadanos. Buenos Aires: Aguilar/ Autea/ Alfaguara/ Taurus, 2004.

PUTNAM, Robert. Comunidade e democracia: A experiência na Itália moderna. Rio de Janeiro: FGV, 1996.

PUTNAM, Robert; GOSS, Kristin. Introduction. In: PUTNAM, Robert (Ed.). Democracies in flux: the evolution of social capital in contemporary society. New York: Oxford University Press, 2002. p. 320.

RODRIK, Dani. Where did all the growth go? External Shocks, Social Conflict and Growth Collapses. Journal of Economic Growth, New York, v. 4, n. 4, p. 385-412, dez. 1999.

SANCHEZ-PARGA, José. Transformaciones del conflicto, decline de los movimientos socials y teoria del desgobierno. Ecuador Debate, Quito, n. 53, p. 19-39, ago. 2001.

SCHUMPETER, Joseph. Capitalism, Socialism and Democracy. London: Allen \& Unwin, 1976.

SILVA, Patricio. Doing politics in a despoliticized society: social change and political deactivation in Chile. Bulletin of Latin American Research, v. 23, n. 1, p. 63-78, 2004.

SOLT, Frederick. Economic inequality and democratic political engagement. American Journal of Political Science, Washington, D.C., v. 52, n. 1, p. 48-60, jan. 2008.

TABELLINI, Guido. Culture and institutions: economic development in the regions of Europe. Working Paper, n.292. Milan: Universita Bocconi, jun. 2005. 73 p.

TOCQUEVILLE, Alexis de. Democracy in America. New York: Vintage Books, 1990.

WEBER, Max. Economía y sociedad. México: Fondo de Cultura, 1983. 